\title{
Classes subalternas, lutas de classe e hegemonia: uma abordagem gramsciana
}

\author{
Ivete Simionatto \\ Universidade Federal de Santa Catarina (UFSC)
}

\section{Classes subalternas, lutas de classe e hegemonia: uma abordagem gramsciana}

Resumo: O artigo procura resgatar, no pensamento de Antonio Gramsci, a concepção de classes subalternas e a sua relação com outras categorias, especialmente, o Estado, a sociedade civil e a hegemonia, como suportes da luta de classes na realidade contemporânea. Aborda, ainda, as relações entre classes subalternas, senso comum e ideologia, bem como as formas de superação tematizadas por Gramsci, através da cultura e da filosofia da práxis. Nesse sentido, num movimento de totalidade, busca recuperar a discussão das classes subalternas, a partir da original formulação gramsciana no âmbito do marxismo, mediante a interação dialética entre estrutura e superestrutura, economia e política. Além do resgate conceitual, apontam-se alguns elementos como subsídios à discussão das formas de subalternidade presentes na realidade contemporânea e as possibilidades de fortalecimento das lutas de tais camadas de classe, sobretudo em momentos de forte desmobilização da participação popular.

Palavras-chave: classes subalternas, lutas de classe, cultura, hegemonia.

\section{Subaltern Classes, Class Struggles and Hegemony : a Gramscian Approach}

Abstract: This article sought to revive the concept of subaltern classes and their relation with other categories, particularly the State, civil society and hegemony in the thinking of Antonio Gramsci, as a support for contemporary class struggles. It also analyzes the relations between subaltern classes, common sense and ideology, as well as the forms of "overcoming" conceptualized by Gramsci, through the culture and philosophy of praxis. The paper revives the discussion of the subaltern classes, based on the original Gramscian formulation in the realm of Marxism, through the dialectic interaction between structure and superstructure, economy and politics. In addition to the conceptual revival, it indicates some elements that can support the discussion of the forms of subalternity found in contemporary reality and the possibilities for strengthening the struggles of these class layers, above all in moments of strong demobilization of popular participation.

Key words: subaltern classes, class sturggle, culture, hegemony. 


\section{Classes subalternas, Estado e sociedade civil}

Na obra gramsciana, as primeiras noções sobre o termo "subalterno"aparecem nos escritos précarcerários, empregadas para designar a submissão de uma pessoa a outras, mais especificamente no contexto da hierarquia militar. É, no entanto, nos Cadernos do Cárcere que Gramsci amplia largamente o significado desse conceito, demarcando seus nexos dialéticos com o Estado, a sociedade civil, a hegemonia, a ideologia, a cultura e a filosofia da práxis. Sugere, no estudo das classes subalternas, a observação de uma série de mediações, tais como suas relações com o "desenvolvimento das transformações econômicas"; sua "adesão ativa ou passiva às formações políticas dominantes"; as lutas travadas a fim de "influir sobre os programas dessas formações para impor reivindicações próprias"; a formação de "novos partidos dos grupos dominantes, para manter o consenso e o controle dos grupos sociais subalternos"; a caracterização das reivindicações dos grupos subalternos e "as formas que afirmam a autonomia" (GRAMSCI, 2002, p.140). Tais indicações, não têm por proposição um programa de estudos historiográfico, mas remetem à complexa tessitura do pensamento gramsciano, em que as reflexões sobre a subalternidade aparecem dialeticamente interligadas com o Estado, a sociedade civil e a hegemonia.

A categoria "subalterno" e o conceito de "subalternidade" têm sido utilizados, contemporaneamente, na análise de fenômenos sociopolíticos e culturais, normalmente para descrever as condições de vida de grupos e camadas de classe em situações de exploração ou destituídos dos meios suficientes para uma vida digna. No pensamento gramsciano, contudo, tratar das classes subalternas exige, em síntese, mais do que isso. Trata-se de recuperar os processos de dominação presentes na sociedade, desvendando "as operações político-culturais da hegemonia que escondem, suprimem, cancelam ou marginalizam a história dos subalternos" (BUTTIGIEG, 1999, p. 30).

Um dos espaços de expressão da dominação constitui-se, sem dúvida, no próprio Estado. Lugar de "unidade histórica das classes dirigentes", o Estado "é, essencialmente, a história dos Estados e dos grupos de Estados", criados a partir do Estado burguês, de novas concepções de Direito, Política, Economia, Educação e, consequentemente, de Ética, estabelecendo uma unidade não apenas no plano jurídico-formal, mas ideologicamente projetada para toda a sociedade. Esta unidade configura-se, para Gramsci (2002, p. 139), como "o resultado das relações orgânicas entre Estado ou sociedade política e "sociedade civil'." A história das classes subalternas está "entrelaçada à da sociedade civil", e só poderá ser unificada quando ambas puderem tornar-se Estado. Para Gramsci (2002, p. 135), "os grupos subalternos sofrem sempre a iniciativa dos grupos dominantes, mesmo quando se rebelam e insurgem: só a vitória 'permanente' rompe, e não imediatamente, a subordinação." Verifica-se, em seu processo histórico, que "na realidade, mesmo quando parecem vitoriosos, os grupos subalternos estão apenas em estado de defesa, sob alerta."

A vida estatal é concebida por Gramsci (2000a, p. 42) de modo dinâmico e processual, "como contínua formação e superação de equilíbrios instáveis [...] entre os interesses do grupo fundamental e os interesses dos grupos subordinados." Isso significa que os interesses do grupo dominante e os dos grupos dominados "implicam-se reciprocamente [...] horizontal e verticalmente", de acordo com a organização econômica e política de cada Estado-nação. O Estado consiste, ainda, em "todo o complexo de atividades práticas e teóricas com os quais a classe dirigente não só justifica e mantém o seu domínio, mas consegue obter o consenso ativo dos governados" (GRAMSCI, 2000a, p. 331). Para Gramsci, o Estado "anula muitas autonomias das classes subalternas", pois a "ditadura moderna" ou contemporânea, ao mesmo tempo em que suprime algumas "formas de autonomia de classe, empenha-se em incorporá-las na atividade estatal: isto é, a centralidade de toda a vida nacional nas mãos das classes dominantes torna-se frenética e absorvente" (GRAMSCI, 1977, p. $303)$, e, nesse processo, torna indistintas as diferenças de classe, fortalecendo a subalternidade. Essa maneira de agir do Estado reveste-se de um grande poder desmobilizador, na medida em que bloqueia as iniciativas da sociedade civil na articulação de interesses e propostas voltados à luta pela superação entre "governantes e governados", dirigentes e dirigidos.

A incorporação da sociedade civil à esfera estatal ocorre através de diferentes mecanismos, especialmente na formação da opinião pública enquanto estratégia de fortalecimento da hegemonia política por parte do Estado em assuntos de seu interesse. $\mathrm{O}$ Estado, na visão gramsciana (2000a, p. 265), "quando quer iniciar uma ação pouco popular cria, preventivamente, a opinião pública adequada, ou seja, organiza e centraliza certos elementos da sociedade civil." Nela "ocorre a luta pelo monopólio dos órgãos da opinião pública: jornais, partidos, parlamento, de modo que só uma força modele a opinião e, portanto, a vontade pública nacional, desagregando os que discordam numa nuvem de poeira individual e inorgânica" (GRAMSCI, 2000a, p. 265). O Estado, apresenta-se, assim, como "um instrumento de aceleração e taylorização", e "opera segundo um plano, pressiona, incita, solicita e pune" (GRAMSCI, 2000a, p. 28). Ou, ainda, utilizando a linguagem gramsciana, pode-se dizer que o Estado "educa o consenso", atra- 
vés dos "aparelhos privados de hegemonia", especialmente através dos meios televisivos e dos grandes monopólios privados da mídia, mecanismos fortalecedores da fragmentação social das classes subalternas, criando um novo "senso comum", "do qual são expelidos a política, a participação, a vida em relação aos outros, o sentido de comunidade" (LIGUORI, 2003, p. 186).

Ao assimilar em seu interior as diferentes camadas de classe, o Estado burguês amplia seu campo de ação, equalizando as classes juridicamente, no sentido de evitar que a ordem seja colocada em perigo. No âmbito da sociedade civil, a classe dominante, através do uso do poder por meios não violentos, contribui para reforçar o conformismo, apostando na desestruturação das lutas das classes subalternas, reduzindo-as a interesses meramente econômicocorporativos. Nenhum grupo social possui condições de superar seus patamares de subalternidade até que não seja capaz de "sair da fase econômico-corporativa para elevar-se à fase da hegemonia político-intelectual na sociedade civil e tornar-se dominante na sociedade política" (GRAMSCI, 1977, p. 460). Além disso, a história episódica e fragmentada das classes subalternas, decorrente de uma concepção de mundo permeada de senso comum e de folclore, impedeas de chegar a elaborações críticas sobre as formas de cooptação e as situações de exploração a que são submetidas cotidianamente. A própria Igreja Católica, enquanto um dos aparelhos privados de hegemonia, contribui fortemente para tanto, especialmente na realidade italiana, com exemplar incidência no fortalecimento da subalternidade de amplas camadas de classe. Para Gramsci (1999, p. 115), as religiões fornecem os principais elementos do senso comum, constituindo-se em uma potência ideológica sobre vastos estratos sociais, ao manifestar-se "das formas mais toscas às mais intelectualizadas." Entretanto, se este era um fenômeno visível na Itália do início do século 20, é hoje observável em escala global, extrapolando o catolicismo, através dos mais variados cultos e religiões e, dada sua imperatividade, produz normas de conduta e modos de agir em diferentes camadas de classe.

A superação da condição de subalternidade requer, para Gramsci, a construção de novos modos de pensar, a elaboração de uma concepção de mundo crítica e coerente, necessária para suplantar o senso comum e tornar as classes subalternas capazes de produzir uma contra-hegemonia. Nesse processo, em suma, aprofundar e aperfeiçoar o conhecimento da realidade impõe-se como condição essencial na luta por sua própria transformação, efetivando-se a "crítica real da racionalidade e historicidade dos modos de pensar" (GRAMSCI, 1999, p. 111), o que poderá ocorrer através da filosofia da práxis, ou seja, do marxismo.

\section{Do senso comum ao bom senso - a filosofia da práxis como caminho de superação}

Se, por um lado, o senso comum representa um "conglomerado" de concepções fragmentárias e desagregadas, produto de concepções filosóficas pretéritas, de "condições de vida passada [...] conservadoras e irracionais", apresenta-se, por outro, como modo de pensar não "enrijecido" e "imóvel", aberto a transformações e enriquecimentos contínuos. O senso comum pode ser entendido, assim, como uma filosofia, mesmo incipiente e fragmentária, pois opina sobre o mundo, formula juizos de valor, os quais, tomados em conjunto, apresentam uma certa organização intelectual e moral da experiência individual e coletiva. Se, para Gramsci (1999, p. 325), "todos são filósofos", isto indica que, na ação prática dos homens, "está contida implicitamente uma concepção de mundo, uma filosofia."

Em Gramsci, o senso comum não permeia somente a visão de mundo das camadas de classe populares, mas, como um "ambiente cultural", como "cultura política", encontra-se presente nos demais grupos e camadas de classe. Entendido como linguagem ou como ideologia, "pode ser identificado em diferentes níveis socioculturais, perdendo o significado de simples "mentalidade popular". Estamos sempre imersos em alguma forma de senso comum, que contribuimos constantemente para modificar" (FROSINI, 2003, p. 173). O senso comum das classes dominantes, contudo, atua como força ideológica, desmobilizadora das iniciativas críticas advindas das camadas subalternizadas.

Todo estrato social tem seu 'senso comum' e seu 'bom senso', que são, no fundo, a concepção da vida e do homem mais difundida. Toda corrente filosófica deixa uma sedimentação de 'senso comum'; é este o documento de sua efetividade histórica. O senso comum não é algo rígido e imóvel, mas se transforma continuamente, enriquecendose com noções científicas e opiniões filosóficas que penetram no costume. O 'senso comum' é o folclore da filosofia e ocupa sempre um lugar intermediário entre o folclore propriamente dito (isto é, tal como é entendido comumente) e a filosofia, a ciência, a economia dos cientistas. O senso comum cria o futuro folclore, isto é, uma fase relativamente enrijecida dos conhecimentos populares de uma certa época e lugar (GRAMSCI, 2000b, p. 209 , grifos do autor).

Senso comum e filosofia são aspectos constitutivos de um mesmo fenômeno, e representam a ligação ideológica com o mundo. Enquanto expressão ideológica, o senso comum remete a um sistema de crenças e valores que, tomados separadamente, não pas- 
sam de uma visão fragmentada do real, sem qualquer coerência. No entanto, são forças constitutivas das relações de poder, e sua crítica representa um momento fundamental para agregar a "vontade coletiva", superar a velha ordem e construir uma nova. Para Gramsci, embora a história das classes subalternas normalmente se manifeste de forma "desagregada e episódica", atravessada pelo senso comum, este é ponto de partida para torná-la coerente e unificada. Seguindo a reflexão marxiana sobre a "solidez das crenças populares", Gramsci (1999, p. 118-19) defende a necessidade de novas crenças, isto é, de "um novo senso comum e, portanto, de uma nova cultura e de uma nova filosofia, que se enraizem na consciência popular com a mesma solidez e imperatividade das crenças tradicionais". Expressas através do senso comum, tais crenças podem ser transformadas em "bom senso", na medida em que as classes subalternas afirmem-se enquanto coletividades e sejam capazes de reelaborar sua visão de mundo a partir de uma cultura forjada na "disciplina interior", e não imposta de forma externa e mecânica.

Compreender o senso comum em sua relação com a ideologia implica, ainda em duas possibilidades analíticas: 1) a existência de diversas expressões do senso comum manifesta-se de maneira espontânea, direta, controlada ou induzida, em permanente transformação e redefinição; 2) se o senso comum apresentase como elemento unificador de um grupo social, consequentemente são diversas as formas como ocorre essa unificação, podendo oscilar entre dois polos opostos: a completa desagregação ou a completa unidade. O primeiro polo aproxima-se historicamente das classes subalternas, caracterizadas por um senso comum e uma linguagem formados de modo desordenado, de forma espontânea, privados de uma periódica atividade de revisão capaz de valorizar os elementos atuais daqueles arcaicos, provenientes de épocas passadas (FROSINI, 2003). Aqui, o senso comum vincula-se ao conceito de conformismo, representando a recepção passiva das ideias e modos de pensar do grupo dominante.

Isto não significa que as classes subalternas sejam passivas e que suas práticas devam ser negadas. Gramsci reflete sobre o contraste entre o pensar e o operar, próprio das classes subalternas, ou seja, a existência simultânea de duas concepções de mundo, expressão de contradições histórico-sociais mais profundas, provenientes das mais variadas heranças do passado. A reflexão gramsciana sugere que uma classe social, mesmo detentora de uma concepção de mundo embrionária e desarticulada, toma emprestada de outro grupo social, por razões de submissão e subordinação intelectual, uma concepção que lhe é estranha, seguindo-a não tanto porque nela acredita, mas por sua conduta não ser independente e autônoma (SIMIONATTO, 2004). Por esta razão, "o homem ativo de massa atua praticamente, mas não tem uma clara consciência teórica desta ação." Mobiliza, contudo, "um conhecimento do mundo na medida em que o transforma", mesmo que "sua consciência teórica esteja historicamente em contradição com o seu agir", consequência do que "herdou do passado e acolheu sem crítica" (GRAMSCI, 1999, p. 103). Ou seja, "afirma-se uma teoria que não tem uma correspondência na prática." Quando "os estímulos para a ação são muito contrastantes", estes levam à "imobilidade", à "irriquietude, isto é, descontentamento, insatisfação" (GRAMSCI, 2001, p. 125).

Gramsci (1999, p. 93-4, grifos do autor) indaga:

[...] é preferível 'pensar' sem disto ter consciência crítica, de uma maneira desagregada e ocasional isto é, 'participar' de uma concepção do mundo 'imposta' mecanicamente pelo ambiente exterior, ou seja, por um dos muitos grupos sociais envolvidos desde sua entrada no mundo consciente -, ou é preferível elaborar a própria concepção de mundo de uma maneira consciente e crítica, ser o guia de si mesmo e não aceitar do exterior, passiva e servilmente, a marca da própria personalidade?

Alterar essa realidade e buscar a completa unidade significa, para Gramsci (1999, p. 103-04), travar uma ampla batalha, que exige, em primeiro lugar, "a compreensão crítica de si mesmo", a ser obtida "através de uma luta de 'hegemonias' políticas, de direções contrastantes, primeiro no campo da ética, depois no da política, atingindo, finalmente, uma elaboração superior da própria concepção do real", mantendo-se a "unidade entre teoria e prática" não como um dado mecânico, mas como um "devir histórico". Trata-se de desconstruir o discurso racional burguês, que se agarra à imediaticidade e à pragmaticidade dos fenômenos sociais, e recriar as práticas sociais no sentido de inová-las, tornálas "concreto pensado" e vinculá-las à uma nova concepção de mundo.

A transformação do senso comum em "bom senso" ocorre por meio da filosofia da práxis, que permite a "superação do modo de pensar precedente", tornando "crítica uma atividade já existente" no seio de "indivíduos singulares". A filosofia da práxis não objetiva "manter os 'simples' na sua filosofia primitiva do senso comum, mas pretende, ao contrário, conduzi-los a uma concepção de vida superior", buscando "forjar um bloco intelectual-moral que torne politicamente possível um progresso intelectual de massa e não apenas de pequenos grupos intelectuais" (GRAMSCI, 1999, p. 100-03).

A teoria possibilita, assim, "acelerar o processo histórico em ato, tornando a prática mais homogênea, coerente, eficiente em todos os seus elementos, isto é, elevando-a à máxima potência." A relação teoria-prá- 
tica "é um ato crítico, pelo qual se demonstra que a prática é racional e necessária ou que a teoria é realista e racional" (GRAMSCI, 1999, p. 260). A teoria, em síntese, "deve fazer-se realidade efetiva" (GRAMSCI, 1999, p. 189), permitindo aos homens "criticar a própria concepção de mundo", tornando-a "unitária e coerente" e elevando-a "até o ponto atingido pelo pensamento mundial mais evoluido" [...]. "Quando a concepção do mundo não é crítica e coerente, mas ocasional e desagregada, pertencemos simultaneamente a uma multiplicidade de homens-massa" ou "homens coletivos"(GRAMSCI, 1999, p. 94).

Ao afirmar-se como concepção de mundo, a filosofia da práxis possibilita superar o senso comum e seu caráter "inercial, passivo e subalterno" (LIGUORI, 2007, p. 123), contribuindo para recuperar a capacidade crítica e analítica mediante a qual as classes subalternas poderão construir propostas alternativas ao projeto dominante. E, ocorrendo de forma orgânica, "restitui ao grupo social uma imagem coerente de si mesmo". O papel dos intelectuais aqui é fundamental e imprescindível, pois, através da filosofia da práxis, têm a possibilidade de "purificar o senso comum", produzindo a consciência crítica e histórica de uma classe social. Se a transformação ocorre de forma caótica, desordenada e casual, as classes subalternas permanecem em sua visão restrita, sem unificação, incapazes de sustentar projetos mais orgânicos e duradouros. Sem teoria revolucionária não há, portanto, prática revolucionária (SADER, 2007).

É a partir da relação entre intelectuais e simples, ou do contato entre "filosofia e senso comum", que se torna possível a elaboração de uma nova concepção de mundo. Ou seja,

[...] trata-se de elaborar uma filosofia - tendo já uma difusão ou possibilidade de difusão, pois ligada à vida prática e implícita nela - que se torne um senso comum renovado com a coerência e o vigor das filosofias individuais. $\mathrm{E}$ isso não pode ocorrer se não se sente, permanentemente, a exigência do contato cultural com os simples (GRAMSCI, 1999, p. 100-01).

Gramsci compreende, assim, que o senso comum, pode ser substituído por uma concepção de mundo mais coerente, não através de uma educação "verbal e livresca", mas no contexto da luta política de uma classe (SIMIONATTO, 2004) "intimamente fundida com um programa político e com uma concepção da história que o povo reconheça como expressão das suas necessidades vitais" (GRAMSCI, 1999, p. 365). Este é o caminho para a construção da hegemonia, uma vez que "a hegemonia realizada [...] significa a crítica real de uma filosofia, a sua real dialética" (GRAMSCI, 1999, p. 242).

\section{Cultura e hegemonia}

Para Gramsci (1999, p. 101), “a relação entre filosofia superior" e senso comum é assegurada pela "política". Superar o senso comum e o modo de pensar corporativo, produto das relações sociais da sociedade burguesa, significa, consequentemente, redirecionar a práxis política no sentido de propiciar às classes subalternas a libertação das formas de pensar homogeneizadas pelo pensamento liberal e o fortalecimento de seus projetos e ações na construção de uma contra-hegemonia. Trilhar esse caminho, no entanto, implica, para o pensador italiano, travar uma batalha não restrita ao terreno econômico, mas abrangendo também os fronts da cultura, das ideias e dos valores.

A cultura é apontada por Gramsci como um dos elementos fundamentais na organização das classes subalternas, capaz de romper com a sua desagregação e abrir caminhos para a construção de uma vontade coletiva, contrapondo-se às concepções de mundo oficiais. Já nos escritos pré-carcerários, Gramsci entende a cultura como um conceito basilar do socialismo. Em 1916, no instigante texto Socialismo e cultura, indica que uma das razões que possibilitava às classes dominantes tomar o poder e mantê-lo não era necessariamente o uso da força bruta, mas, em grande medida, a dominação cultural e sua capacidade de difusão de ideias, valores, filosofias e visões de mundo por toda a sociedade. A cultura apresentase, assim, como condição necessária ao processo revolucionário, pois "toda a revolução foi precedida de um intenso trabalho de crítica, de penetração cultural, de permeação de ideias através de agregados, de homens antes refratários e preocupados em resolver dia a dia, hora a hora" os problemas individuais, dissociados dos "outros que se encontravam na mesma situação” (GRAMSCI, 2004, p. 59). Entendida de forma crítica, a cultura é instrumento de emancipação política das classes subalternas, o amálgama, o elo de ligação entre os que se encontram nas mesmas condições e buscam construir uma contra-hegemonia.

A transformação do senso comum em uma concepção de mundo independente e autônoma só poderá ocorrer, segundo Gramsci, mediante a formação de uma nova cultura, que possibilite realizar a crítica às ideias, aos valores e às práticas impostos às classes subalternas, especialmente pela chamada "alta cultura"1. Esta, ao negar a existência de diferenciações com a cultura popular, não compreendendo o senso comum, aparta-se dele, age

[...] como força política externa, $[\ldots]$, limita o pensamento original das massas populares de uma maneira negativa, sem influir positivamente sobre elas, como fermento vital de transformação 
interna do que as massas pensam, embrionária e caoticamente, sobre o mundo e a vida (GRAMSCI, 1999, p. 114-5).

As preocupações de Gramsci com a cultura relacionam-se, assim, à compreensão de que a luta pela emancipação das classes subalternas não se restringe à esfera econômica, uma vez que, dadas as condições de subalternidade a que estas historicamente foram submetidas, torna-se necessário o encaminhamento de uma "reforma intelectual e moral", independente do domínio ideológico da classe burguesa. Gramsci (1999, p. 295) insiste na "valorização do fato cultural, da atividade cultural, de uma frente cultural como necessária, ao lado das frentes meramente econômicas e políticas", pois,

Criar uma nova cultura não significa apenas fazer individualmente descobertas 'originais'; significa também, e sobretudo, difundir criticamente verdades já descobertas, 'socializá-las' por assim dizer; e, portanto, transformá-las em base de ações vitais, um elemento de coordenação e de ordem intelectual e moral. $\mathrm{O}$ fato de que uma multidão de homens seja conduzida a pensar coerentemente e de maneira unitária a realidade presente é um fato 'filosófico' bem mais importante e 'original' do que a descoberta, por parte de um 'gênio' filosófico, de uma nova verdade que permanece como patrimônio de pequenos grupos intelectuais (GRAMSCI, 1999, p. 96, grifos do autor).

A batalha cultural apresenta-se, por conseguinte, como elemento central na construção da hegemonia, na conquista do consenso e da direção político-ideológica por parte das classes subalternas. Possibilita a construção de uma nova visão de mundo e de uma proposta transformadora de sociedade a partir de 'baixo', fazendo com que toda uma classe participe de um projeto radical que "envolva toda a vida do povo e ponha cada qual, brutalmente, diante das próprias responsabilidades inderrogáveis"'(GRAMSCI, 2002, p.268).

Enquanto totalidade, a hegemonia significa a unificação entre estrutura e superestrutura, atividade de produção e de cultura, particular econômico e universal político. Busca-se elevar ao máximo de universalidade possível o ponto de vista dos grupos subalternos e superar os interesses particulares, articulando-os num projeto cuja expressão é a "vontade coletiva nacional-popular”. Retomando Marx, para reafirmar que "os homens agem tomando consciência dos conflitos da estrutura no terreno das ideologias", Gramsci (1999, p. 320) entende que a hegemonia é a síntese da esfera econômica e da consciência crítica, devendo "ser considerada como uma afirmação de valor gnosiológico e não puramente psicológico e moral."
A irrefutável relação entre cultura, política e economia, ou, nas palavras de Coutinho (2003, p. 75), a "articulação entre subjetividade e objetividade, entre liberdade e causalidade, entre particularidade e universalidade", encontra-se no cerne das preocupações do autor italiano, para quem a economia não se reduz à produção de objetos e mercadorias, mas remete, antes de tudo, ao modo como os homens estabelecem suas relações sociais, transformando a si e a própria sociedade. Assim, se a estrutura econômica abarca "o conjunto das relações sociais", ela forma, ao lado da superestrutura, uma totalidade, ou seja, o "bloco histórico". Novamente resgatando Marx, Gramsci observa que, não sendo a formação da consciência crítica "limitada ao conflito entre as forças materiais de produção e as relações de produção", uma vez que "os homens adquirem consciência de sua posição social e de seus objetivos no terreno das superestruturas, isso significa que entre estrutura e superestrutura existe um nexo necessário e vital" (GRAMSCI, 1999, p. 389), remetendo-nos ao conceito de “"bloco histórico”, no qual, precisamente, as forças materiais são o conteúdo e as ideologias são a forma" (GRAMSCI, 1999, p. 238). Pode-se afirmar, assim, que todas as práticas sociais são mediatizadas "em diversos graus, por todo o tecido social, pelo conjunto das superestruturas" (GRAMSCI, 2000b, p. 20).

"Os fatos da superestrutura", no entanto, não “devem ser abandonados a si mesmos, a seu desenvolvimento espontâneo, a uma germinação casual e esporádica", alerta Gramsci (2000a, p.28). Por isso é importante compreender que sua proposta não se restringe a um "ato mental" ou ao "reino das ideias autogeradas", mas abrange, também, o campo das estruturas materiais. Ao afirmar o plano das ideias, o pensamento gramsciano não pode ser reduzido a "uma exaltação idealista das restrições materiais historicamente dadas" (COUTINHO, 2003, p.76). Gramsci jamais deixou de identificar os antagonismos estruturais do modo de produção capitalista, bem como seus parâmetros de dominação e exploração no contexto da ordem socioeconômica. Não há, em sua obra, uma rejeição da economia ou da esfera estrutural, mas um diagnóstico das novas determinações do capitalismo, dos problemas em jogo e das formas de luta para enfrentá-los. Vale ressaltar, assim, que sua concepção de hegemonia não se restringe à esfera superestrutural, compreendendo, também, a esfera econômica, visto que, "se a hegemonia é ético-política, não pode deixar de ser também econômica, não pode deixar de ter seu fundamento na função decisiva que o grupo dirigente exerce no núcleo decisivo da atividade econômica" (GRAMSCI, 2000a, p. 48).

A luta pela hegemonia nas sociedades de capitalismo avançado, contudo, não se trava, para Gramsci, apenas nas instâncias econômica e política (relações materiais de produção e poder estatal), mas também 
na esfera da cultura. A elevação cultural das massas assume importância decisiva neste processo, para que possam libertar-se da pressão ideológica das classes dirigentes e elevar-se à condição destas últimas. A conquista da hegemonia e a construção de uma vontade coletiva, nas sociedades ocidentais, implicam, como já observado, a realização de uma ampla "reforma intelectual e moral"'. Se a hegemonia é resultante "das atividades e iniciativas de uma ampla rede de organizações culturais, movimentos políticos e instituições educacionais que difundem sua concepção de mundo e seus valores capilarmente pela sociedade" (BUTTIGIEG, 2003, p. 46), isso não compreende apenas a transmissão e a disseminação de ideias e valores dos grupos dominantes para as classes subalternizadas; ao contrário reforça igualmente a capacidade dos grupos subordinados em elaborar suas demandas e aspirações, suas possibilidades de luta, ou seja, a construção de uma contra-hegemonia, manifestada quando ocorre

[...] a passagem nítida da estrutura para a esfera das superestruturas complexas; é a fase em que as ideologias geradas anteriormente se transformam em 'partido', entram em confrontação e lutam, até que uma delas ou pelo menos uma combinação delas tenda a prevalecer, a se impor, a se irradiar por toda a área social, determinando, além da unicidade dos fins econômicos e políticos, também a unidade intelectual e moral, pondo todas as questões em torno das quais ferve a luta não no plano corporativo, mas num plano 'universal', criando assim a hegemonia de um grupo social fundamental sobre uma série de grupos subordinados (GRAMSCI, 2000a, p. 41, grifo do autor).

Cultura e política relacionam-se, para Gramsci, à perspectiva de transformação social, às formas de aceitação ou contestação das relações de poder existentes na sociedade. Ao criticar a cultura dominante, $o$ pensador aponta as formas pelas quais os sujeitos coleletivos podem lhe fazer frente, intervindo politicamente através de práticas concretas, seja nos partidos, nos sindicatos, nos movimentos sociais e em seus modos de engajamento nas lutas cotidianas.

Fortalecer esse movimento, consequentemente, significa superar o senso comum, o modo de pensar desorganizado e folclórico. Significa alcançar um pensar crítico e histórico que se constrói atra-
Cultura e política relacionamse, para Gramsci, à perspectiva de transformação social, às formas de aceitação ou contestação das relações de poder existentes na sociedade. cussão de suas situações comuns, poderão chegar a um nível de cultura sempre mais crítico em relação às situações impostas pelo atual modo capitalista de produção. Tal possibilidade, entretanto, só poderá ser construída a partir das "contradições materiais da vida prática" das condições objetivas, das necessidades históricas (LIGUORI, 2007) e das formas de resistência forjadas no cotidiano das classes subalternizadas como possibilidade de enfrentamento à hegemonia capitalista contemporânea.

A relação entre cultura e política, remete, ainda, à importância da linguagem, tanto dos intelectuais quanto da população, por seu poder de interpretar suas lutas e dar visibilidade a suas concepções de mundo, ora distantes do discurso dominante ora atravessadas por ele. Toda a linguagem, para Gramsci (1999, p. 94-95), “contém os elementos de uma concepção do mundo e de uma cultura." Representa a capacidade de "elaborar a própria concepção de mundo consciente e criticamente [...] escolher a própria esfera de atividade, participar ativamente na construção da história e do mundo, ser guia de si mesmo e não mais aceitar do exterior, passiva e servilmente, a marca da própria personalidade." A relação entre linguagem e política está também relacionada à luta pela hegemonia, na medida em que pode significar o domínio dos mais cultos sobre os menos cultos, de uma nação sobre outra, dos grupos dominantes sobre as classes dominadas através de diferentes mecanismos como a mídia, as formas de comunicação virtual introduzidas na era da internet e ainda a manipulação ideológica utilizada em programas de governo, conforme se verificou ao longo das últimas décadas sob o ideário da privatização e da desresponsabilização do Estado, especialmente no âmbito dos direitos sociais. Em nome da eficiência e eficácia do mercado, provocou-se a desmaterialização e fragmentação progressiva dos direitos sociais e econômicos, substituídos por programas focalizados de combate à pobreza e por medidas de cunho assistencialista (ADELANTADO, 2008).

Merece destaque, neste eixo de reflexão, a expansão das formas de dominação no contexto do capitalismo atual, provocando modalidades diversas de subalternização e de desmobilização das camadas de classe populares. Temos assistido ao "apassivamento das lutas sociais, encapsuladas em reivindicações de cunho imediato (corporativas) e circunscritas a níveis de consciência elemenvés da luta, a partir dos problemas práticos vividos pelas classes subalternas, as quais, mediante a dis- tares" (FONTES, 2008, p. 33). A fraca oposição popular vincula-se também ao crescimento da mani- 
pulação política das camadas de classe subalternas, especialmente através dos programas compensatórios de combate à pobreza. Atravessados por práticas clientelistas e de cooptação, tais programas, assumidos por boa parte dos governos da América Latina, têm amortecido os conflitos sociais e, consequentemente, provocado a passividade e a apatia das camadas de classe subalternizadas com o arrefecimento das organizações das formas de protesto e de luta. Fortalecem a espontaneidade "como modo normal de intervenção política” (BOITO, 2003, p. 26), fazendo com que estas classes permaneçam desagregadas, impotentes. No campo ideológico, contribuem para "manter cativa a simpatia política difusa desse setor popular pauperizado e desorganizado" (BOITO, 2003, p.26). A ausência de recursos de ação coletiva e suas dificuldades de organização causam profundas desagregações no plano das relações sociais impedindo que necessidades e demandas se transformem em direitos e estes, em decorrência, em plataformas de luta política mais ampla. Nesse cenário, a participação política e o protagonismo popular perdem centralidade e os programas de combate à pobreza acabam por operar um verdadeiro transformismo pela assimilação, por parte do Estado, de boa parte de setores das classes subalternas mediante práticas clientelistas e reprodutoras das desigualdades.

Conforme se afirmou no início deste texto, recuperar as formas de "adesão ativa ou passiva" das classes subalternas às políticas dominantes, a caracterização de suas reivindicações e as lutas que podem travar juntamente com outros institutos organizativos da sociedade civil, representantes dos interesses populares, são caminhos e possibilidades para afirmar a sua autonomia e construir projetos societários para além dos limites postos pela hegemonia burguesa, nos marcos do capitalismo contemporâneo.Dessa situação de subalternidade pode-se emergir quando se assume a consciência do significado do próprio operar, da efetiva posição de classe, da natureza das hierarquias sociais e políticas. Quando se elabora, enfim, uma nova concepção de política, de Estado, de sociedade, superando a concepção de mundo imposta mecanicamente a partir do ambiente externo, da sociedade oficial de modo passivo, substituindo a "espontaneidade" pela "direção consciente", por uma visão de mundo coerente, crítica e renovada. Há que se reconhecer que esse é um processo "longo, difícil, cheio de contradições, de avanços e de recuos, de desdobramentos e reagrupamentos" (GRAMSCI, 1999, p. 104), que exige persistência e pressão advindas do contrapoder popular.

\section{Referências}

ADELANTANDO, J. Limites y oportunidades de las politicas sociales focalizadas para el desarrollo de la democracia en America Latina. Barcelona, 2008. Texto digitado.

BOITO, A. A hegemonia neoliberal no governo Lula. Crítica marxista. São Paulo: Editora Revan, n. 17, p. 11-36, 2003.

BUTTIGIEG, J. Educação e hegemonia. In: COUTINHO, C. N.; TEIXEIRA, A. de P. (Org.). Ler Gramsci, entender a realidade. Rio de Janeiro: Civilização Brasileira, 2003, p. $39-50$.

. Sulla Categoria gramsciana di 'subalterno'. In: BARATA, G.; LIGUORI, G. (Org.). Gramsci da un secolo all'altro. Roma: Editori Riuniti, 1999, p. 27-38.

COUTINHO, C. N. O conceito de política nos Cadernos do Cárcere. In: COUTINHO, C. N.; TEIXEIRA, A. de P. (Org.). Ler Gramsci, entender a realidade. Rio de Janeiro: Civilização Brasileira, 2003, p. 67-82.

FONTES, V. Capitalismo, imperialismo, movimentos sociais e lutas de classes. Revista em Pauta. Faculdade de Serviço Social do Estado do Rio de Janeiro: Rio de Janeiro, n. 21, p. 23-36, jul. 2008.

FROSINI, F. Gramsci e la filosofia. Roma: Carocci Editore, 2003.

GRAMSCI, A. Cadernos do cárcere. Tradução de Carlos Nelson Coutinho com a colaboração de Luiz Sergio Henriques e Marco Aurélio Nogueira. Rio de Janeiro: Editora Civilização Brasileira, 1999. v. 1.

Cadernos do cárcere. Tradução de Carlos Nelson

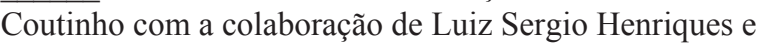
Marco Aurélio Nogueira. Rio de Janeiro: Editora Civilização Brasileira, 2000a. v. 3.

. Cadernos do cárcere. Tradução de Carlos Nelson Coutinho com a colaboração de Luiz Sergio Henriques e Marco Aurélio Nogueira. Rio de Janeiro: Editora Civilização Brasileira, 2000b. v. 2.

. Cadernos do cárcere. Tradução de Carlos Nelson Coutinho com a colaboração de Luiz Sergio Henriques e Marco Aurélio Nogueira. Rio de Janeiro: Editora Civilização Brasileira, 2001.v. 4.

. Cadernos do cárcere. Tradução de Carlos Nelson Coutinho com a colaboração de Luiz Sergio Henriques e Marco Aurélio Nogueira. Rio de Janeiro: Editora Civilização Brasileira, 2002 .v. 5. 
. Escritos Politicos. Tradução de Carlos Nelson Coutinho. Rio de Janeiro: Editora Civilização Brasileira, 2004. v. 1 .

- Quaderni del carcere. Edição crítica de Valentino Gerratana. Turim: Einaudi, 1977, 4 v.

LIGUORI, G. Estado e sociedade civil: entender Gramsci para entender a realidade. In: COUTINHO, C. N.; TEIXEIRA, A. de P. (Org.). Ler Gramsci, entender a realidade. Rio de Janeiro: Civilização Brasileira, 2003, p. 173-188.

LIGUORI, G. Roteiros para Gramsci. Tradução de Luiz sérgio Henriques. Rio de Janeiro: Editora da UFRJ, 2007.

SADER, E. Crise hegemônica na América Latina. Revista em Pauta. Faculdade de Serviço Social do Estado do Rio de Janeiro: Rio de Janeiro: Editora Revan, n. 19, p. 15-26, 2007.

SIMIONATTO, I. Gramsci, sua teoria. Influência no Brasil, incidência no Serviço Social. São Paulo-Florianópolis: Cortez/UFSC, 2004.

\section{Notas}

1 Otermo "alta cultura"éutilizado por Gramscina crítica contra oEnsaio populardeBukharin. Escreve Gramsci(1999, p. 11415): "OEnsaio popular se equivoca ao partir (implicitamente) do pressuposto de que, a esta elaboração de uma filosofia original das massas populares, oponham-se os grandes sistemas das filosofias tradicionais e a religião do alto clero, isto é, a concepção do mundo dos intelectuais e da alta cultura. Na realidade, estes sistemas são desconhecidos pelas multidões, não tendo eficácia direta sobre o seu modo de pensar e agir. Isto não significa, por certo, que eles estejam desprovidos inteiramente de eficácia histórica; mas esta eficácia é de outra natureza. Estes sistemas influem sobre as massas populares como força política externa, como elemento de força coesiva das classes dirigentes e, portanto, como elemento de subordinação a uma hegemonia exterior."

2 Nas reflexões sobre a "reforma intelectual e moral" destacase o papel conferido por Gramsci aos intelectuais e ao partido político, que possuem a tarefa permanente de organizar a classe na luta pela construção da hegemonia.

\section{Ivete Simionatto}

Pós-Doutorado no European University Institute (EUI), Itália

Doutorado em Serviço Social pela Pontifícia Universidade Católica de São Paulo (PUC/SP)

Professora no Curso de Serviço Social e no Programa de Pós-Graduação em Serviço Social (PPGSS), na Universidade Federal de Santa Catarina (UFSC)

\section{UFSC - PPGSS}

Campus Universitário Reitor João David Ferreira Lima

Bairro Trindade

Florianópolis - Santa Catarina

Brasil 